II Congreso Internacional Estéticas Híbridas de la Imagen en Movimiento: Identidad y Patrimonio

\title{
El Colapso (Les Parasites, 2019): discurso audiovisual online y crisis ecosistémica
}

\author{
Lorena Rodríguez Mattalía ${ }^{a}$. \\ a Profesora Titular de la Universidad Politécnica de Valencia, Facultad de Bellas Artes, \\ Departamento de Escultura (e-mail: lorod@esc.upv.es). Este artículo ha sido fruto de una \\ investigación llevada a cabo en el seno del proyecto I + D: "Humanidades ecológicas y \\ transiciones ecosociales. Propuestas éticas, estéticas y pedagógicas para el Antropoceno" \\ (PID2019-107757RB-I00), financiado por la Agencia Estatal de Investigación, Ministerio de Ciencia \\ e Investigación, Gobierno de España.
}

\section{Abstract}

The COVID-19 crisis, which has impacted on our way of life, has brought us into contact with the vulnerability of the system. Added to this picture are the warnings that steady growth on finite natural resources is impossible and that our way of life is deteriorating the environment. All this serves as a breeding ground for a dystopian vision of the future, to the extent that there is a line of "collapsist" thinking that maintains that we are heading towards a collapse that, in fact, has already taken hold in the so-called "underdeveloped" countries.

These concerns are present in our cultural landscape, where the audiovisual medium plays an important role in today's culture of online connectivity. In this context, we focus on the series L'Effondrement (The Collapse, 2019) produced by Canal + and

directed by a collective of three young filmmakers, Les Parasites (The Parasites), who broadcast their short films on their YouTube channel.

The series or miniseries has 8 dystopian chapters of about 20 minutes that show what this hypothetical collapse would be like: lack of supplies, organisation of ecovillages, nuclear power stations without maintenance, creation of welfare islands for the rich, etc. The audiovisual approach of the series is very interesting, as each chapter is a shotsequence filmed with a shoulder-mounted camera that provokes an immersive sensation due to the absence of fragmentation of space-time.

In addition, the series has functioned as an online event, since, after its premiere, it was broadcast openly accompanied by making off, reports and debates, which makes it a clear example of how the audiovisual, through online platforms, can "make present", 
bring to the forefront issues that are often silenced or treated with little rigour; issues called to build a collective imaginary outside hegemonic thought.

Keywords: audio-visual, ecosystem collapse, environment, sequence shot

\section{Resumen}

La crisis del COVID-19, que ha impactado en nuestro modo de vida, nos ha puesto en contacto con la vulnerabilidad del sistema. A este panorama se añaden las advertencias de que es imposible un crecimiento constante en base a recursos naturales finitos y que nuestro modo de vida está deteriorando el medioambiente. Todo ello sirve como caldo de cultivo para una visión distópica del futuro, hasta el punto de que existe una línea de pensamiento "colapsista" que mantiene que nos encaminamos hacia un colapso que, de hecho, ya se ha instalado en los llamados países "subdesarrollados".

Estas preocupaciones están presentes en nuestro panorama cultural, donde el medio audiovisual tiene un importante papel en la actual cultura de la conectividad online. En dicho contexto, nos centramos en la serie L'Effondrement (El Colapso, 2019) producida por Canal $+y$ dirigida por un colectivo de tres jóvenes realizadores, Les Parasites (Los Parásitos), que difunde sus cortometrajes en su canal de YouTube.

La serie o miniserie tiene 8 distópicos capítulos de unos 20 minutos que muestran cómo sería ese hipotético colapso: falta de suministros, organización de ecoaldeas, centrales nucleares sin mantenimiento, creación de islas de bienestar para ricos, etc. Es muy interesante la apuesta audiovisual de la serie, pues cada capítulo es un plano-secuencia filmado en cámara al hombro que provoca una sensación inmersiva por la ausencia de fragmentación del espacio-tiempo.

Además, la serie ha funcionado como evento online, pues, posteriormente a su estreno, se difundió en abierto acompañada de making off, reportajes y debates, lo cual la convierte en un claro ejemplo de cómo el audiovisual, a través de las plataformas online, puede "hacer presente", traer al primer plano cuestiones a menudo silenciadas o tratadas con poco rigor; cuestiones llamadas a construir un imaginario colectivo fuera del pensamiento hegemónico.

Palabras clave: audiovisual, colapso ecosistémico, medioambiente, plano secuencia 


\section{Introducción}

Marzo de 2020: calles vacías, población confinada, problemas con ciertos suministros en los supermercados... Todo un escenario distópico donde la pandemia de COVID-19 logró poner en jaque el statu quo de las sociedades actuales. No obstante, poco más de un año después, podemos afirmar que no nos llevó a un colapso total, e incluso tenemos ahora la sensación de estar saliendo de dicha crisis.

Pero, ¿̇y se hubieran sumado más factores?: falta de suministros de artículos o servicios de primera necesidad (comida, agua, luz, incluso Internet...); ello causado, por ejemplo, por el inminente agotamiento de las fuentes de energía no-renovable (petróleo y otros combustibles fósiles), o alguna catástrofe medioambiental de gran magnitud o una suma de varias.

Es el panorama que se plantea la serie francesa L'Effondrement (El Colapso, Guillaume Desjardins, Jérémy Bernard y Bastien Ughetto, 2019) producida y estrenada por Canal +. Con una asombrosa puntería, estos tres jóvenes realizadores - que forman el colectivo Les Parasites (Los Parásitos) ${ }^{1}$ - presentan 8 capítulos, de unos 20 minutos cada uno (por lo cual puede ser considerada una "miniserie"), donde muestran cómo sería un hipotético colapso de las actuales sociedades acomodadas ${ }^{2}$ : desde la falta de suministros básicos en supermercados o gasolineras, pasando por la reacción de las clases altas, la organización de alguna alternativa posible, el peligro de la falta de mantenimiento de las centrales nucleares o el abandono de los sectores de población más débiles.

Se insertan así en todo un ambiente cultural actualmente en desarrollo -con estudios, investigaciones, films, series, producción artística, etc.- en torno a las graves preocupaciones sobre la insostenibilidad de nuestro modo de vida. Desde los años 70

\footnotetext{
${ }^{1}$ Les Parasites son 3 exalumnos de la EICAR (École internationale de Création Audiovisuelle et de Réalisation de París) que llevan desde 2013 realizando cortometrajes para cuya distribución $\begin{array}{llll}\text { recurren a su canal de YouTube: } & \end{array}$ https://www.youtube.com/channel/UCqS1gDNHEX3FgJ8dPfSuRoQ [Consulta: 16 de mayo de 2021].

${ }^{2}$ Nos referimos a aquellos y aquellas que vivimos con plena disponibilidad de agua, alimentos, energía, objetos de consumo y tecnología, pues hay que tener en cuenta que el $90 \%$ de la población del planeta posee menos del $20 \%$ de la riqueza disponible y que un $45 \%$ de la riqueza está en manos del $1 \%$ de la población más rica. Son datos extraídos de informe Global Wealth Report del Credit Suisse Research Institute (2019), disponible en: https://www.creditsuisse.com/es/es/private-banking/learn-more-about-market-trends/global-wealth-report2019.html [Consulta: 1 de junio de 2021].
} 
se van sucediendo claras advertencias ${ }^{3}$ de que no se puede mantener el crecimiento constante de un sistema en base a unos recursos finitos y que estamos afectando a los ecosistemas de todo el planeta, hasta el punto de denominar a nuestra era como "Antropoceno" ${ }^{4}$. A lo cual hay que añadir las profundas desigualdades sociales que se vieron duramente agravadas por la crisis económica iniciada en 2008, que sirvió de excusa para duros recortes de orden neoliberal en el llamado Estado del Bienestar.

Todo ello nos anuncia que nuestro actual modelo de civilización no va a poder mantenerse mucho más allá de la segunda parte del siglo XXI (Riechmann, 2013). Esta sospecha, cada vez más apremiante, está impactando en la cosmovisión occidental hasta el punto de que existe una corriente "colapsista" - que comentaremos más adelante- que mantiene que el crecimiento incontrolado del hiperconsumismo va a sobrepasar los límites de lo posible, lo cual llevaría a un colapso por sectores (suministros básicos, crisis política y económica, de seguridad, de salud pública, etc.); un colapso que se ha instalado ya en los llamados países "subdesarrollados" y que acabará llegando a América del Norte y Europa.

Y a ello hay que sumar que la actual crisis provocada por el COVID-19, que ha modificado - por ahora de forma temporal- nuestras relaciones personales y que ha impactado seriamente en la economía mundial, nos ha puesto en contacto de forma insoslayable con la vulnerabilidad de nuestra forma de vida.

Este artículo tiene como objetivo, a través del estudio del caso concreto de El Colapso (2019), estudiar cómo el medio audiovisual tiene un importante papel que cumplir en el panorama descrito, dada su centralidad en la actual cultura de la imagen y la conectividad online. Estudiaremos en primer lugar la dialéctica entre distopía y utopía para entender el alcance de las distopías que invaden nuestro panorama cultural. Analizaremos después la apuesta audiovisual de la citada serie, pues cada capítulo es un único plano secuencia realizado con cámara al hombro, donde el espectador/a, ante la sensación de verosimilitud provocada por la ausencia de fragmentación del espacio-

\footnotetext{
${ }^{3}$ En los años 60-70 del pasado siglo, se publicaron varios ensayos e informes sobre el impacto de la industrialización sobre el medioambiente, que marcaron el inicio de la concienciación ecologista. Por ejemplo, el emblemático Primavera silenciosa (Carson, 2016), publicado por primera vez en 1962, estudió el impacto contaminante de la industria química. En 1972 se publicó Los límites del crecimiento, un informe encargado al MIT por el Club de Roma que alertaba sobre nuestra capacidad de supervivencia en la Tierra, que estaría en peligro a partir de las primeras décadas del siglo XXI; informe que ha sido revisado en varias ocasiones (1992, 2004, 2012), matizando sus conclusiones.

4 El concepto de "Antropoceno", fue lanzado por primera vez por el premio Nobel de química Paul Crutzen, refiriéndose a que el nombre de la época geológica actual debería incorporar el impacto del ser humano sobre el planeta. La denominación se formalizó en el texto "The Anthropocene" (Crutzen y Stoermer, 2000).
} 
tiempo fílmico, se siente partícipe de la escena. Finalmente, trataremos cómo la serie ha funcionado como un evento online, pues sus realizadores negociaron que, además de ir estrenando los capítulos en la plataforma de pago, posteriormente se fueran difundiendo mensualmente en abierto, en su canal de YouTube. Además, el 12 de noviembre de 2020 difundieron toda la serie en su canal, acompañada de vídeos de making off, reportajes y debates sobre los temas "sistémicos" - utilizando sus palabras- que les preocupan.

\section{2. ¿Distopía vs utopía?}

El Colapso (2019) es, como hemos señalado ya, una serie que se inserta en el amplio panorama de producciones audiovisuales de base distópica. Para entender bien su alcance, conviene detenernos en definir qué entendemos por distopía.

Las distopías ${ }^{5}$, o utopías negativas, son ficciones que retratan organizaciones sociales nocivas, comúnmente ambientadas en el futuro, que toman impulso en el siglo $\mathrm{XX}$ siguiendo la línea de H. G. Wells, Aldous Huxley, George Orwell y Ray Bradbury ${ }^{6}$. Según López Keller (1991), en el siglo pasado se sucedieron serias críticas a las construcciones utópicas por varias razones: por un lado, si las utopías planteaban, desde aproximadamente el siglo $\mathrm{XVI}^{7}$, la fabulación de una organización social perfecta, varios autores $^{8}$ comenzaron a criticar su impulso colectivizador que, desde el punto de vista del capitalismo más liberal, sacrifica las libertades individuales buscando el funcionamiento óptimo de la sociedad. Por otro lado, desde una posición más progresista, se criticaba el mecanicismo de la organización utópica, donde todo se controla en aras de una verdad monopolizada. De hecho, como afirmaba H. G. Wells: "Dudo yo de que nadie haya experimentado jamás el deseo de ser un ciudadano de la República de Platón (...)." (2000, p. 9).

Es importante señalar que, mientras que las utopías tenían como punto de partida la fe en el progreso de la ciencia y la tecnología como origen del bienestar de la humanidad, el siglo XX fue demostrando que, a pesar de sus numerosos avances científicos, no se consiguió la justicia social a la que podríamos aspirar. De hecho, el siglo pasado ha estado plagado de guerras y desigualdades, sin olvidar el inicio de los terribles efectos

\footnotetext{
${ }^{5}$ Término acuñado finalizando el siglo XIX por John Stuart Mill.

${ }^{6}$ La máquina del tiempo (H. G. Wells, 1898), Un mundo feliz (Aldous Huxley, 1932), 1984 (George Orwell, 1949) y Fahrenheit 451 (Ray Bradbury, 1953). Todas estas novelas tienen una o varias adaptaciones cinematográficas.

${ }^{7}$ Los orígenes de la utopía como género literario se remontan a La República de Platón, siendo después formulado el concepto por Thomas More, en su famosa obra Utopía, de 1516.

${ }^{8}$ Como Popper (2010), por ejemplo.
} 
en el medioambiente del desarrollismo sin medida; todo lo cual hemos heredado en la actualidad, donde cabría preguntarse si la pandemia del COVID-19 no es, aparte de una crisis sanitaria con consecuencias sociales y económicas, una catástrofe medioambiental más, tal y como ha sugerido Stella Kyriakides, comisaria de Salud de la Comisión Europea 9 .

Por ello, no nos extraña que, desde aproximadamente la mitad del siglo XX, el pesimismo se haya extendido (López Keller, 1991, p. 13) y haya contagiado nuestra cosmovisión actual. Autores como Horowitz (1969) juzgaron dicho pesimismo como conservador, alegando que el miedo al porvenir puede hacernos añorar el pasado y acatar el presente. No obstante, no debemos olvidar que una de las funciones de la utopía es la de denuncia ${ }^{10}$, de forma que las distopías pueden funcionar también denunciando los posibles derroteros perniciosos de las sociedades establecidas, mostrando las consecuencias futuras de tendencias que ya existen, pero sin buscar refugio en el pasado o el presente (Martorell, 2012).

En nuestra opinión, si el miedo las desata, dicho miedo no es tanto al futuro, como al presente: la distopía “(...) está mucho más anclada en el presente que las utopías clásicas; no parte de la razón o de los principios morales para elaborar un modelo ideal, sino que deduce un mundo futuro de pesadilla a partir de la extrapolación de realidades presentes" (López Keller, 1991, p. 15).

Por tanto, las distopías hacen proyecciones de futuro, a veces de forma alarmista, es cierto, pero cuya utilidad reside en sacar a la luz los problemas actuales más peligrosos. Así mismo, ese "reverso tenebroso de la utopía" (Santos, 2019, p. 11) sirve también para analizar los sueños utópicos, buscando sus deficiencias y potencialidades que podrían resultar dañinas respecto a los valores de igualdad y justicia social.

${ }^{9}$ Ya en 2019 el Informe de la Agencia Europea del Medio Ambiente (AEMA), relacionaba claramente degradación ambiental y salud pública en Europa (European Environment Agency, 2019) y, en septiembre de 2020, tras el inicio de la pandemia, Stella Kyriakides, comisaria de Salud y Seguridad Alimentaria de la Comisión Europea afirmaba: "La COVID-19 ha sido una nueva señal de alarma que nos ha llevado a cobrar conciencia inmediata de la relación existente entre nuestros ecosistemas y nuestra salud, así como de la necesidad de enfrentarnos a los hechos: el modo en que vivimos, consumimos y producimos son perjudiciales para el clima y afectan negativamente a nuestra salud." (Comisión Europea, 2020). Ver también las conclusiones de las investigaciones llevadas a cabo en el IS Global, Instituto de Salud Global de Barcelona (O'callaghan, 2020).

${ }^{10}$ López Keller (1991) resume en tres las funciones de la utopía: 1. función de denuncia (donde las utopías sirven para criticar las carencias del mundo real); 2 . función analítica (donde las utopías estudian el entorno, para después proponer mejoras); 3. función de incentivo (donde muestran que otras formas de organización social podrían desarrollarse). 


\section{El Colapso (2019): una apuesta audiovisual}

Ese auge de las distopías, cuyo inicio fue literario, ha sido especialmente acuciado en las producciones audiovisuales, donde destacan films de muy variado cariz: desde el cine de Vanguardias, con el mítico Metrópolis (Fritz Lang, 1927); pasando por la Nouvelle Vague con Alphaville, une étrange aventure de Lenny Caution (Jean-Luc Godard, 1965) o Fahrenheit 451 (François Truffaut, 1966); hasta algunos de los films más taquilleros de los años 70-80, como la trilogía de Mad Max (George Miller, 19791985), además de films de culto como Blade Runner (Ridley Scott, 1982) ${ }^{11}$. El s. XX se cerró con ejemplos como 12 monos (Terry Gilliam, 1995) o Matrix (Lana y Lilly Wachowsk, 1999); para llegar a los 2000 con, entre muchos otros, La carretera (John Hillcoat, 2009) ${ }^{12}$ y, por supuesto, la serie que nos ocupa ${ }^{13}$.

Como decíamos más arriba, El Colapso tiene 8 capítulos de unos 20 minutos ${ }^{14}$ cada uno, que muestran algunos de los efectos de ese posible colapso, sin entrar a desgranar sus causas, sino centrándose en ejemplos de sus consecuencias: falta de suministro en supermercados y gasolineras, abandono de los sectores poblacionales más débiles como son los ancianos, peligro por falta de mantenimiento de las centrales nucleares, etc. Además, se centran en las reacciones de la población: desde el sálvese quien pueda de mucha gente, pasando por la capacidad de autoprotección por encima de quien sea de las clases altas y la creación de alternativas elitistas (una isla autogestionada, solo para ricos que hayan pagado ese "seguro de vida"), sin olvidar el empeño ético de algunos por ayudar al otro o la organización de una ecoaldea como modo de supervivencia y creación de otro tipo de comunidad más sostenible e igualitaria. Se va desgranando así una historia abierta, muy bien documentada, donde ciertos personajes o líneas de acción se cruzan y enfrentan al espectador/a a un impactante encuentro con lo real sin edulcorantes.

\footnotetext{
${ }^{11}$ Últimamente se han estrenado secuelas de estos films: Mad Max: Furia en la carretera (George Miller, 2015) y Blade Runner 2049 (Denis Villeneuve. 2017).

${ }^{12}$ Hemos citado solamente algunos ejemplos destacados dentro del muy abundante corpus de films distópicos que invade nuestras pantallas desde, fundamentalmente, los años 70 del siglo pasado.

${ }^{13}$ En cuanto a las series de base distópica, desde el inicio de la segunda década de los 2000, se ha dado también un auge, con ejemplos como Black Mirror (Charlie Brooker, 2011) o El cuento de la criada (Bruce Miller, 2017), que acaba de lanzar su cuarta temporada. O incluso la producción española La valla (Daniel Écija, 2020).

${ }^{14}$ La duración total de toda la miniserie es de 160 minutos.
} 
Cada capítulo se centra en un escenario concreto, como indican los títulos: 1: "El supermercado $(D+2)^{15}$ "; 2: "La gasolinera $(D+5)$ "; 3: "El aeródromo $(D+6)$ "; 4: "La aldea (D +25)"; 5: "La Central (D +45)"; 6: "La Residencia (D +50)"; 7: "La Isla (D +170)"; 8: "La emisión (D -5)". Como se puede deducir de las indicaciones temporales entre paréntesis, la historia va avanzando a saltos en el tiempo (2 días después del colapso, 5 días, 25 días después, etc.); salvo para el último capítulo, donde se da un retroceso a 5 días antes.

Estamos, por tanto, ante una clara apuesta por trabajar conscientemente con el espacio-tiempo, uno de los parámetros centrales del arte audiovisual, fundamentalmente por medio de tres estrategias. En primer lugar, se da una unidad espacial en cada capítulo, donde todo gira entorno a esos lugares citados en los títulos. En segundo lugar, tenemos una serie de 7 elipsis definidas, donde se producen esos saltos en el tiempo hasta llegar a 170 días después del colapso. El último capítulo, en cambio, rompe esa linealidad entrecortada para dar un salto al pasado, antes del colapso. Es destacable el hecho de que el día 0, el día del colapso, es justamente aquello en torno al cual todo gira, pero que no aparece en la serie, siendo elidido seguramente por su complejidad y globalidad.

Pero lo más destacable es cómo decidieron los realizadores mostrar ese espaciotiempo: sin cortes, evitando la fragmentación del montaje en 8 largos planos secuencia que corresponden a cada capítulo. Para lograrlo, Les Parasites han hecho un trabajo magistral de puesta en escena (preparación de movimientos y diálogos de los actores y actrices, control de las localizaciones, etc.) y de movimientos de cámara y encuadres, que deben de estar perfectamente coreografiados con los personajes, de manera que si uno de ellos sale de un coche, por ejemplo, la cámara lo precede o lo sigue (en el capítulo de la isla, es notorio cómo la cámara se desplaza, junto con la protagonista, de la playa a una lancha, al velero, al agua...). No obstante, como ellos mismos no dudan en reconocer ${ }^{16}$, el desafío técnico del rodaje los obligó a realizar algunos cortes ${ }^{17}$; de hecho, son 4 los capítulos rodados realmente en plano secuencia y otros 4 donde los pocos cortes han sido disimulados, normalmente aprovechado movimientos rápidos de cámara. No obstante, la experiencia de los/as espectadores/as es de unidad espaciotemporal, por lo cual, ese empeño inmersivo continua vigente.

\footnotetext{
${ }^{15}$ En el original francés, junto a cada título hay una indicación temporal: $(\mathrm{J}+2)$ para el primer capítulo, donde al "J" se refiere a "jour", es decir, día.

${ }^{16}$ En la entrevista a Les Parasites por Timothe Beaulieu en su canal CALME TOI: Invités \#1 - Les

Parasites (Timothe Beaulieu, 2020): https://www.youtube.com/watch?v=xBa91cHCD9E

[Consulta: 23 de mayo de 2021].

${ }^{17}$ Además de realizar algunas correcciones en postproducción, como añadir alguna pista de sonido aparte de la música, por ejemplo.
} 
Si revisamos el hilo narrativo de la serie, en los capítulos 1, 2, 4, 5 y 6, el espacio-tiempo citado en los títulos condensa la acción de los personajes: un supermercado en el segundo día tras el colapso, donde ya se nota la falta de suministros en varios productos y donde un joven que trabaja de dependiente ayuda a un grupo de amigos a llevarse comida para escapar de París, pues no pueden pagarla (las tarjetas no funcionan y no tienen dinero en metálico); una gasolinera, donde los dueños ya no aceptan dinero, sino que realizan un desigual trueque de unos pocos litros de gasolina por la comida que trae la larga cola de clientes ansiosos por alejarse lo más posible de los núcleos urbanos, clientes que se transformarán en saqueadores a partir del disparo de un policía y el agotamiento del depósito de la gasolinera ${ }^{18}$; una aldea en medio del campo (autogestionada a modo de ecoaldea, donde, de hecho, participan parte de los jóvenes que aparecen en el primer capítulo), donde llega un grupo de personas huyendo de la ciudad y piden asilo, lo cual se ve en peligro por la desconfianza y agresividad de un reducido grupo de visitantes (entre los cuales está un padre con dos niñas que ya había utilizado la violencia para escapar de la gasolinera); una central nuclear, donde un grupo de trabajadores/as lucha contrarreloj para enfriar, con agua sacada a cubos de un río cercano, la combustión nuclear que, sin mantenimiento, acaba explotando; y una residencia, donde solo $\mathrm{Marco}^{19}$, un trabajador que sigue haciéndose cargo de los ancianos, lucha por sacarlos adelante, hasta que un grupo de personas (entre las que está la mujer que era dueña de la gasolinera) les roba sus últimas provisiones, lo cual le obliga a tomar una decisión definitiva.

En los capítulos 3 y 7, en cambio, la unidad espacial es relativa, pues tanto el aeródromo como la isla son los lugares a donde se dirigen los protagonistas. En el capítulo 3, comenzamos en una gran mansión, a 6 días del colapso, donde un adinerado hombre de unos 50 años es apremiado a llegar en menos de una hora a un aeródromo desde donde va a despegar un avión que lo llevará a una isla (refugio de un grupo de privilegiados millonarios para casos de emergencia). Tras abandonar a su amante, consigue robar una avioneta - que, como buen privilegiado, sabe pilotar- y dirigirse a otro aeródromo donde le espera una segunda oportunidad. En el capítulo 7, sin duda el más complejo de $\operatorname{rodar}^{20}$, partimos de una playa donde, después de 170 días de supervivencia, una mujer (que resulta ser la esposa del citado millonario) ha atracado

\footnotetext{
${ }^{18}$ Este capítulo es el que rodaron en primer lugar como experiencia piloto para presentarlo a Canal + y solicitar financiación, que obtuvieron del programa Canal + Création Decalée.

${ }^{19}$ Protagonizado por Bastien Ughetto, miembro del colectivo Les Parasites.

${ }^{20}$ Como afirman los realizadores, la localización de este capítulo en un velero en el mar les obligó a hacer numerosas tomas y a rodar durante 3 días seguidos, no como otros capítulos que sí pudieron rodarse en una sola jornada. Ver: la entrevista Invités \#1 - Les Parasites (Timothe Beaulieu, 2020): https://www.youtube.com/watch?v=xBa91cHCD9E [Consulta: 23 de mayo de 2021].
} 
su velero para buscar comida; vemos cómo lucha encarnizadamente por llegar con su velero a la isla donde ella también tiene reserva (isla que solo vemos vagamente en el horizonte), consiguiendo burlar los drones que la custodian al mostrar su tarjeta "V.I.P".

Finalmente, el capítulo 8, "La emisión", rompe con esa tónica general: su título se refiere a un acontecimiento, no a un lugar, aunque la acción se centra en el acceso a un plató de TV, donde un grupo de activistas ecologistas se empeñan, 5 días antes del colapso, en lanzar un mensaje de alerta a la población, aprovechando una entrevista en televisión a la Ministra de Medioambiente (que resulta ser la mujer del velero, esposa del millonario). El portavoz del grupo, un ingeniero agrónomo que había trabajado en un proyecto sobre la cuestión climática junto con la actual ministra, consigue colarse en el plató y debatir con ella y, a pesar de las burlas del presentador y del cinismo de ésta, consigue lanzar su mensaje de advertencia (el cual, de hecho, sale en el primer capítulo, en un monitor de televisión del supermercado), que resulta ser un resumen muy concentrado de algunos planteamientos ecologistas actuales: el "crecimiento verde" no existe, es un engaño para ganar más dinero; no es posible mantener un crecimiento infinito en un planeta finito; hace 50 años que se viene avisando de la insostenibilidad del sistema. El personaje, con voz entrecortada, cansado del escepticismo continuo de su audiencia, acaba afirmando: "no evitaremos el colapso, pero podemos sobrevivir" ${ }^{21}$.

No nos es posible, dada la reducida extensión de este texto, analizar en profundidad cada capítulo y algunas de sus escenas más épicas, por ejemplo, la de cómo un padre de dos niñitas que van cantando en el coche - como si fueran de excursión - se convierte en un peligroso pistolero en una gasolinera; o cómo la famosa ministra, mujer más que acomodada, lucha por sobrevivir a toda costa en el mar, 175 días después de ese debate en televisión donde pedía a la población tranquilidad y confianza en las instituciones $^{22}$.

Decir solamente que, para los/as espectadores/as, que podemos seguir a los personajes en tiempo real por los espacios donde luchan por sobrevivir, el ritmo de esos planos secuencia nos resulta trepidante, lo cual consigue ponernos en situación y plantearnos que, realmente, podríamos ser nosotros/as los/as protagonistas de estas historias cruzadas.

\footnotetext{
${ }^{21}$ Palabras extradías del discurso de Jacques, el ingeniero activista, en el capítulo 8 de El Colapso (2019).

22 Es notable también que, tras el debate ante las cámaras, ella interpela a su excolega, diciéndole: "No habrá colapso, Jacques, no en casa". Encarna así ese espejismo de invulnerabilidad que tienen sociedades occidentales de los países más ricos. Una invulnerabilidad de la cual sí disfrutan individualmente la ministra y su marido que, gracias a su riqueza y contactos, tienen el seguro de la isla que los espera.
} 
Hay que señalar que el recurso de utilizar largos planos secuencia para crear la sensación de continuidad, se ha dado en el cine en contados pero notables casos, como en Rope (1948), de Alfred Hitchcock, film rodado en 10 tomas que dan la sensación de ser una sola (ya que se enmascaran los escasos cambios de plano). Otros films que utilizan este recurso pero con otras intenciones son, por ejemplo, La Chambre (1972), de Chantal Akerman, donde la cámara realiza una panorámica circular que recorre la casa de la realizadora, funcionando como una especie de autorretrato donde podemos observar sus objetos personales y a Akerman tumbada. Un ejemplo más actual y con una intención más cercana a la serie analizada, es el film titulado 1917 (2019) de Sam Mendes, donde aparentemente ${ }^{23}$ dos planos secuencia (el primero de más de una hora) nos muestran cómo dos jóvenes soldados británicos, en la Primera Guerra Mundial, tienen que atravesar territorio alemán para alertar de una emboscada que provocaría la muerte de cientos de compañeros. Un caso extremo es el cine de Dogma95 ${ }^{24}$, donde los realizadores daneses que firmaron su manifiesto (Von Trier y Vinterberg, 1995) se impusieron una serie de normas ${ }^{25}$ con el fin de distanciarse del cine más comercial, entre las cuales estaba la unidad de espacio-tiempo en sus films.

Lo que sí que está claro es que el empeño de no cortar la aparente unidad del plano resulta en El Colapso un acierto estilístico que da coherencia a la serie, pues a la vez que le da sobriedad estética - aunque añade dificultades técnicas de las cuales han sabido sacar partido- logra crear más empatía en los/as espectadores/as, en consonancia con el mensaje crítico respecto a la insostenibilidad de la sociedad en la que vivimos. Como firman los propios realizadores ${ }^{26}$, su objetivo no era simplemente hacer un film apocalíptico, sino llevar al espectador/a al aquí y ahora, encerrándolos/as en esos planos-secuencia que los/as colocan en el hipotético pero muy verosímil caso de tener que vivir esas situaciones extremas.

\footnotetext{
${ }^{23}$ Son planos secuencia simulados, como en el caso de Rope (Hitchcock, 1948).

${ }^{24}$ Se inicia en Copenhague, en 1995.

${ }^{25}$ Como es la obligatoriedad de rodar en exteriores, sin accesorios adicionales ni decorados; la prohibición de usar música o de añadir pistas de sonido posteriormente, además de no poder utilizar trucajes o filtros en postproducción; etc. Estas condiciones autoimpuestas aparecen en el "Manifiesto Dogma95" y el "Voto de Castidad" firmados por Lars Von Trier y Thomas Vinterberg, en Copenhague, el 13 de marzo de 1995 (Von Trier y Vinterberg, 1995).

${ }^{26}$ En la entrevista a Les Parasites por Timothe Beaulieu en su canal CALME TOI: Invités \#1 - Les Parasites (Timothe Beaulieu, 2020): https://www.youtube.com/watch?v=xBa91cHCD9E [Consulta: 23 de mayo de 2021].
} 


\section{Un fenómeno online}

Otro aspecto fundamental que nos queda por destacar de la serie es que, como señalábamos en la introducción, esta no se ha limitado a ser difundida solamente en la plataforma Canal +, sino que ha formado parte de la apuesta de sus realizadores por la difusión online de sus contenidos de forma gratuita.

Desde 2013, los jóvenes realizadores Guillaume Desjardins, Jérémy Bernard y Bastien Ughetto, llevan difundiendo sus cortos de ficción en su canal de YouTube ${ }^{27}$, como por ejemplo el corto Amor artificial (Les Parasites, 2014) ${ }^{28}$, realizado en el marco del concurso "48 Hours Project" de 2014. Para dicho concurso, tal vez por humildad o por espíritu rebelde, se autodenominaron "parásitos", lo cual dio lugar al nombre del colectivo. Posteriormente, habiendo conseguido financiación ${ }^{29}$ para su primer proyecto de más envergadura, no dudaron en negociar que la difusión de El Colapso (2019) se haría también en abierto a lo largo del año y que el 12 de noviembre de 2020 se difundiría al completo de forma gratuita en su propio canal online. Como ellos mismos dicen en su vídeo de presentación ${ }^{30}$, "la realidad alcanzó la ficción”, pues quién les iba a decir que dicha difusión se haría en plena pandemia mundial.

En su citado canal, además de sus creaciones, difunden otros proyectos, como su taller de creación audiovisual Atelier $7^{31}$, o su participación en el proyecto StoryTANK ${ }^{32}$, donde un grupo de investigadores y guionistas ${ }^{33}$ se preguntan cómo generar relatos que se enfrenten a los desafíos actuales desde un punto de vista crítico, donde pasemos de los relatos del individuo a relatos de ayuda mutua y colectiva.

Sobre estos mismos valores intentan basar su producción audiovisual, no dudando en compartir lo que saben a partir de su experiencia. Por ejemplo, Guillaume Desjardins

${ }^{27}$ https://www.youtube.com/channel/UCqS1gDNHEX3FgJ8dPfSuRoQ [Consulta: 4 de mayo de 2021].

${ }^{28}$ Disponible en: https://www.youtube.com/watch?v=iXkwVkvNBAo [Consulta: 1 de junio de 2021]

${ }^{29}$ Producida por ET BIM, STUDIO +, CANAL + y SINCHRONE MEDIAS; además del apoyo del Centre National du Cinéma et l'image animée (CNC), de Francia.

${ }^{30}$ L'Éffrondrement, Nouvelles Les Parasites (Jérémy Bernard y Guillaume Desjardins, 2020), disponible en: https://www.youtube.com/watch?v=FvmzRhTdOLO\&t=1s [Consulta : 18 de mayo de 2021].

${ }^{31}$ https://atelier-7.org/ [Consulta: 8 de junio de 2021]. Dicho taller consiste en una residencia de un mes más sobre la creación audiovisual. Se celebró por primera vez en verano de 2020 y este verano 2021 conocerá su segunda edición.

${ }^{32}$ Canal de YouTube: https://www.youtube.com/channel/UCuLqLVKE11vANNatunE2ZKQ [Consulta: 8 de junio de 2021].

${ }^{33}$ Como, por ejemplo, Ollivier Pourriol o Philippe Barrière. 
tiene un canal de YouTube llamado RougeVertBleu ${ }^{34}$ donde comparte sus conocimientos técnicos sobre rodaje y postproducción, realizando tutoriales y desvelando cómo rodaron la serie.

A nuestro entender, este empeño por la difusión online no es solamente una estrategia para conseguir más audiencia - ahora llamada "seguidores" - sino una manera de vertebrar un discurso político crítico y de crear comunidad en torno a la reflexión sobre la sostenibilidad de nuestras sociedades. El Colapso contribuye con un formato audiovisual a la discusión sobre la hipótesis de que el statu quo actual de nuestras sociedades no se va a poder mantener por mucho más tiempo, de ahí que ambienten la serie en un contexto muy parecido a nuestro presente y no en un lejano futuro distópico.

De hecho, hay en Internet todo un debate en torno al colapsismo que empezó a coger fuerza ya iniciados los años 2000 y que tiene detrás toda una serie de referentes ${ }^{35}$ e investigaciones $^{36}$ a tener en cuenta, de manera que no se trata simplemente de teorías "conspiranoicas" - como se dice últimamente-. No nos es posible hacer una referencia completa de dicho debate, simplemente destacamos el interesante diálogo establecido en la revista VientoSur entre dos investigadores destacados en el discurso ecosocial: Jorge Riechmann (2020) y Jaime Vindel (2020), que polemizan sobre el alcance de la idea de colapso, preguntándose cuál tiene que ser la postura de la militancia ecologista de izquierdas. Además de intentar conocer sus causas, consecuencias y posible marco temporal, las preguntas en torno al tema son numerosas: ¿se debe exigir medidas que readapten nuestro sistema para evitar ese posible colapso?, ¿o aceptar su inevitabilidad y pensar en cómo paliar sus efectos devastadores?; y también y más importante, ¿es posible evitar el colapso sin tocar los basamentos del sistema capitalista?, ¿es el colapso solamente una amenaza a nuestra civilización, o es también una oportunidad de diseñar las cosas desde cero?

En este sentido, a nuestro entender, la serie comentada hace una aportación muy interesante al citado debate, poniéndole imágenes y sonidos a esas potencialidades e

\footnotetext{
${ }^{34}$ https://www.youtube.com/channel/UCrElillgRtGIYlbR0QLHb5g [Consulta: 9 de junio de 2021].

${ }^{35}$ Solamente en nuestro ámbito hispanohablante, son numerosos los investigadores, activistas medioambientales y militantes de izquierdas que reflexionan sobre la posibilidad de un colapso civilizatorio, como es el caso de Manuel Casal Lodeiro (2016), Miguel Fuentes (2017) o Demián Morassi (2021).

${ }^{36}$ Es destacable también el libro Colapso: porqué unas sociedades perduran y otras desaparecen, de Jared Diamond (2006), donde estudia numerosos ejemplos a la largo de la historia de sociedades que han colapsado por, entre otras cuestiones, causas medioambientales y el impacto human en su entorno; como es el caso de la Isla de Pascua, cuyo colapso se ha atribuido a la sobrepoblación y devastación del ecosistema entre los siglos XVI y XVIII.
} 
invitando al espectador/a a ponerse en la piel de un ciudadano/a del "primer mundo" que, casi de repente, se encontrara con lo real de su supervivencia.

\section{Conclusiones}

Comenzábamos este texto preguntándonos por el alcance de las distopías y las razones de su profusión en la producción audiovisual contemporánea. Aparte del posible impacto desmovilizador que muchas distopías pueden tener, inoculando la idea de que el futuro está perdido, que nada podemos hacer para evitarlo y que solo nos queda refugiarnos en un presente que se nos pinta como un mal menor, es también notable la capacidad crítica de ciertas distopías, de aquellas que alertan sobre tendencias presentes que pueden desencadenar graves consecuencias, pero ante las cuales todavía se puede oponer resistencia.

El Colapso, es un espectáculo apabullante que nos encara con parte de nuestros temores en torno a la fragilidad de un futuro muy cercano, tanto que lo hemos vislumbrado con toda esta crisis del COVID-19:

(...) en estos momentos de incertidumbre en el que hemos sido testigos en primera persona de la fragilidad de un sistema que no ha resultado tan fiable como esperábamos, su mensaje adquiere un tono revelador e inquietantemente cercano en el que la realidad y la ficción se funden y se confunden. (Martínez, 2020)

A nuestro entender, los 7 primeros capítulos son una exposición descarnada de cómo el "sálvese quien pueda" tiene una prevalencia tremenda en las reacciones de la población, lo cual estaría en la línea de la afirmación de Riechmann ${ }^{37}$ ante la posición optimista que ve en un posible colapso la oportunidad para construir una sociedad más justa: "no esperemos demasiado del fin del mundo" (Riechmann, 2020). Pero no hay que olvidar los capítulos sobre la central nuclear, la residencia y, en parte, la aldea, que alimentan la esperanza de que la solidaridad y apuesta por la ayuda mutua también son valores muy fuertes en el ser humano.

El capítulo 8, "La emisión", pretende ir un poco más allá, aconsejando a los/as espectadores/as que estén atentos/as, que se informen, que no se queden con los mensajes hegemónicos de los medios y los discursos planos de los políticos de turno. De hecho, el portavoz del grupo ecologista que irrumpe en el plató, en su mensaje de alerta, da algunas pistas de lo que puede hacer la audiencia: intentar anticiparse a lo que va a ocurrir, reorganizarse en torno a grupos de ayuda mutua, salir de un sistema que se tambalea, en cuanto haya signos graves de alerta.

\footnotetext{
${ }^{37}$ Citando a Stanislaw Jerzy Lec.
} 
Esta serie resulta ser un claro ejemplo de cómo el audiovisual, a través de las plataformas digitales en abierto, puede hacer presente, construir discurso, traer al primer plano cuestiones que están en muchos discursos contrahegemónicos a menudo silenciados, tratados con poco rigor o con intereses partidistas; cuestiones - como la sostenibilidad no publicitaria, la que realmente se preocupa por cómo organizar sociedades justas desde el punto de vista ecosocial y no simplemente por convertir "lo verde" en una oportunidad más de negocio- que deben de entrar en nuestra agenda si queremos construir un imaginario colectivo fuera del pensamiento único.

\section{Referencias}

CARSON, R. (2016). La primavera silenciosa. Barcelona: Crítica.

CASAl Lodeiro, M. (2016). La izquierda ante el colapso de la civilización industrial. Guadalajara: Editorial La Oveja Roja.

COMISIÓN EUROPEA (2020). Combatir la contaminación y el cambio climático en Europa mejorará la salud y el bienestar, especialmente para los más vulnerables, comunicado de prensa. Web oficial de la UE. <https://ec.europa.eu/commission/presscorner/detail/es/ip_20_1571>.

CREDIT SUISSE RESEARCH INSTITUTE (2019). Global Wealth Report. Suiza: Credit Suisse Group AG.

CRUtzen, P. J. y StOERmer, E. F. (2000). The Anthropocene. IGBP NewsLetter, The International Geosphere-Biosphere Programme (IGBP): A Study of Global Change of the International Council for Science (ICSU), 17-18. <http://www.igbp.net/download/18.316f18321323470177580001401/1376383088452/NL41.pdf $>$.

DiAmond, J. (2006). Colapso: porqué unas sociedades perduran y otras desaparecen. Caracas: Editorial Arte S.A.

EUROPEAN ENVIRONMENT AGENCY (2019). Healthy environment, healthy lives: how the environment influences health and well-being in Europe. EEA Report, no21. Copenhagen: Publications Office of the European Union. <https://www.eea.europa.eu/publications/healthyenvironment-healthy-lives>.

FUENTES, M. (2017). ¿Superación del Capitalismo o Colapso de la Civilización? (I), Rebelión, <https://rebelion.org/autor/miguel-fuentes/>.

Horowitz, I. L. (1969). Formalización de la teoría general de la ideología y la utopía, Buenos Aires: Eudeba.

López KelleR, E. (1991). Distopía: otro final de la utopía. REIS, Revista Española de Investigaciones Sociológicas, 55, 7-23.

Martínez, B. (2020). 'El colapso', la serie que retrata el derrumbe de la civilización, elPeriódico <https://www.elperiodico.com/es/series/20200809/tomatelo-en-serio-el-colapso-derrumbecivilizacion-apocalipsis-8068220> 
Martorell Campos, F. (2012). Notas sobre la dominación y temporalidad en el contexto postmoderno a propósito de la distopía. Astrolabio 13, 274-286.

MARTORELl CAmpos, F. (2015). Transformaciones de la utopía y la distopía en la postmodernidad. Tesis doctoral. Universitat de València, Facultat de Filosofia i Ciències de I'Educació, Departament de Filosofía, Àrea d' Estètica i Teoria de les Arts.

Martorell Campos, F. (2019). Soñar de otro modo. Cómo perdimos la utopía y de qué forma recuperarla. Valencia: Editorial La Caja Books.

MoRASSI, D. (2021). La aritmética de la vida entre el hormigón, Revista 15/15|15. <https://www.15-15-15.org/webzine/2021/05/17/la-aritmetica-de-la-vida-entre-el-hormigon/>.

MoRe, TH. (1998) Utopía. Madrid: Alianza.

O'CALLAGHAN, C. (2020). Salud planetaria y COVID-19: la degradación ambiental como el origen de la pandemia actual, IS Global, Barcelona: Instituto de Salud Global.<https://www.isglobal.org/healthisglobal/-/custom-blog-portlet/salud-planetaria-y-covid19-la-degradacion-ambiental-como-el-origen-de-la-pandemia-actual/6112996/0>

POPPER, K. (2010). La sociedad abierta y sus enemigos. Barcelona: Paidós Ibérica.

Riechmann, J. (2013). El Siglo de la Gran Prueba. Tenerife: Baile del Sol.

RieCHMANN, J. (2020) Sobre los puntos ciegos del "colapsismo": diálogo con Jaime Vindel, Revista VientoSur, <https://vientosur.info/sobre-los-puntos-ciegos-del-colapsismo-dialogo-con-jaimevindel/>.

SANTOS, A. (2019). Tiempos de ninguna edad. Distopía y cine. Madrid: Cátedra.

VINDEL, J. (2020). ¿Ecosocialismo versus Colapsismo? Notas para una discusión, Revista VientoSur, <https://vientosur.info/ecosocialismo-versus-colapsismo-notas-para-una-discusion/>

Von Trier, L. y Vinterberg, Th. (1995). Manifiesto del Dogma 95 y Voto de Castidad. Dogme95.dk Un tributo al Dogme95 oficial. <http://www.dogme95.dk/dogma-95/>

WeLLS, H. G. (2000). Una utopía moderna. Barcelona: OCEANO.

\section{Referencias audiovisuales}

12 Monkeys (12 Monos. Dir. Terry Gilliam). [Film]. Universal Pictures. 1995.

1917 (Dir. Sam Mendes). [Film]. Neal Street Productions, DreamWorks SKG, New Republic Pictures. 2019.

Alphaville, une étrange aventure de Lemmy Caution (Dir. Jean-Luc Godard). [Film]. Athos Films, Chaumiane, Filmstudio. 1965.

Black Mirror (Dir. Charlie Brooker). [Serie en plataforma Netflix]. Zeppotron, Channel 4. 2011.

Blade Runner (Dir. Ridley Scott). [Film]. Warner Bros., Ladd Company, Shaw Brothers. 1982. 
Lorena Rodríguez Mattalía

Blade Runner 2049 (Dir. Denis Villeneuve). [Film]. Warner Bros., Scott Free Productions, Thunderbird Films, Alcon Entertainment, 16:14 Entertainment, Torridon Films. 2017.

El cuento de la criada (Dir. Bruce Miller). [Serie en plataforma HBO y Paramount Channel]. MGM Television, Hulu. 2107.

Fahrenheit 451 (Dir. François Truffaut) [Film]. Anglo Enterprises, Vineyard Film. 1966.

L'Effondrement (El Colapso. Dir. Les Parasites: Guillaume Desjardins, Jérémy Bernard y Bastien Ughetto). [Serie en plataforma Canal+]. Et Bim, Studio+, Canal+ y Sinchrone Medias. 2019.

La Chambre (Dir. Chantal Akerman). [Film]. Paradise Films. 1972.

La valla (Dir. Daniel Écija). [Serie en plataforma AtresPlayer Premium y Atresmedia Televisión]. Globomedia, Good Mood. 2020.

Mad Max (Dir. George Miller). [Film]. Kennedy Miller Productions, Crossroads, Mad Max Films. 1979.

Mad Max: Fury Road (Mad Max: Furia en la Carretera. Dir. George Miller). [Film]. Kennedy Miller Productions, Warner Bros., Village Roadshow. 2015.

Matrix (Dir. Lana y Lilly Wachowsk). [Film]. Warner Bros., Village Roadshow, Groucho Film Partnership. 1999.

Metropolis (Dir. Fritz Lang). [Film]. U.F.A. 1927.

Rope (La soga. Dir. Alfred Hitchcock). [Film]. Warner Bros., Transatlantic Pictures. 1948.

The Road (La Carretera. Dir. John Hillcoat) [Film]. Dimension Films, 2929 Productions. 2009.

Timothe Beaulieu. (2020). Invités \#1 - Les Parasites [Vídeo]. YouTube. (https://www.youtube.com/watch?v=xBa91cHCD9E. 